\title{
THE DECISION OF INTRAUTERINE GROWTH RETARDATION FROM ULTRASONOGRAPHIC EXAMINATIONS WITH NEURAL NETWORKS
}

\author{
Fikret Gürgen1, Emrah Oొmal1, Füsun G. Varol'2 \\ ${ }^{1}$ Computer Eng. Dept., Boğaziçi University \\ Bebek, 80815 Istanbul - Türkiye \\ \{E-mail: gurgen@boun.edu.tr\} \\ and \\ ${ }^{2}$ Gynecology and Obstetric Dept., Trakya University \\ Edirne - Türkiye
}

\begin{abstract}
Our purpose is to make decision of intrauterine growth retardation (IUGR) through single and multiple ultrasonographic fetal growth assessments using a neural network (NN). This study was undertaken to show if a feedforward NN can learn nominal growth curves of head circumference (HC), abdominal circumference (AC), and $\mathrm{HC} / \mathrm{AC}$ ratio versus gestational age and can help doctors in diagnosis of IUGR. Weekly (from 1 to 4 weeks) ultrasonographic examinations are taken as input to NN. A feedforward NN is used as a function approximator. Back propagation (BP) algorithm is used to optimize connection weights using samples from nominal curves. It was observed that a NN can improve the accuracy of the decision of IUGR by the multiple weekly examinations which mean monitoring the dynamic process of a change in size over time. It was concluded that the applicability of NNs to determination of IUGR is possible and it is a fruitful line of inquiry for further work.
\end{abstract}

KEY WORDS: Nominal growth curves (HC, AC, HC/AC) versus gestational age, symmetric and asymmetric Intrauterine Growth Retardation (IUGR), Neural Network (NN), function approximation.

\section{INTRODUCTION}

This study supports a computer-based diagnostic approach in IUGR. Therefore, it aids to clinical decision. Infants who are truly growth retarded (IUGR) and at risk for increased morbidity and mortality should be differentiated from infants who have reached their genetic growth potential and are not at increased risk [2]. Here, three major components of this statement are emphasized. First, the population studied should be defined in terms of race, gender, altitude and genetic growth potential. Second, the growth variable measured such as birth weight (BW) should be clearly defined and reproducible. Third, the limits of normality in the population for the variable studied should be described in detail. However, studies use arbitrary statistical limits based on population means (e.g. $<10^{\text {th }}$ percentile, $<3^{\text {rd }}$ percentile, $>2$ standard deviation (SD) below the mean) to define abnormal growth. 
Several methods have been proposed in the search for early and precise diagnosis of impaired fetal growth prospective trials with new techniques are becoming common in evaluating diagnostic methods for IUGR. Diagnostic methods that have been described as useful range from maternal historic or clinical factors, through indicators of fetal well being, to ultrasound examination or fetal blood flow. It is not surprising that the usefulness of these methods is uncertain and varies widely from one report to another. The most significant changes in the diagnosis of growth retardation have come in the field of ultrasonography. The single most significant factor is the accuracy of gestational age. The results approximate gestational age determinations by reliable last menstrual period. Fetal body growth parameters have been studied including biparietal diameter (BPD), head circumference (HC) and head area (HA), abdominal circumference (AC) and area. Changes in these parameters have been claimed to be useful in detection of impaired fetal growth. A combination of these measurements provides additional clues to body proportions and asymmetry of growth.

A feedforward NN is employed to approximate the functions of normal fetuses (including SGA and LGA) and fetuses with sIUGR and aIUGR [6,7,13]. Individual growth functions (in this case, three growth curves) are determined by single and multiple weekly examinations which are introduced to the NN. As the emerging technique of last decade [3], NN has the duty of pattern classification, which can be thought as regression analysis where input variables are associated with outcomes according to a specified relationship to obtain a predictive model. The technique excels in correlating many variables that, taken alone, may not be statistically significant but as a group provide added information to best model an outcome. The feedforward structure of $\mathrm{NN}$ consists of a weighted combination of nonlinear units to best model the input data.

This study is conducted to determine if single and multiple ultrasonographic examinations are useful for predicting IUGR. For the demonstration of applicability purpose, symmetric and asymmetric IUGR (sIUGR and aIUGR) curves are used for the input of the $\mathrm{NN}$. Nominal curves of $\mathrm{HC}, \mathrm{AC}$ and $\mathrm{HC} / \mathrm{AC}$ ratio vs gestational age for normal, small for gestational age (SGA) and large for gestational age (LGA) and transition regions for sIUGR and aIUGR are coded on the connection weights of a NN. Weekly examinations (from 1 to 4 weeks) are considered. An increasing success rate for the increasing number of examinations are obtained.

\section{MATERIAL AND METHODS}

\section{Detection of IUGR}

In this study, we examine the applicability of a NN to detection of IUGR. Block diagram of a proposed IUGR diagnosis system may be as shown in Figure 1. The system receives weekly ( up to 4 weeks) ultrasound examinations as inputs and produces an output decision about the normality of examined fetus.

Patterns of growth for fetuses with sIUGR and aIUGR on the nominal curves of normal, SGA and LGA are taken from Chudleigh, (1994) and are shown in Table 1. Table 1 is used for the experiments. Weekly examination up to 4 weeks are presented to $\mathrm{NN}$ as input by dividing data into two groups: training data and test data. The training data are used for the computation of weights of the network and test data are for examination of the decision results. A gaussian noise with zero mean and small variance is introduced to training data. The input values for a weekly ultrasound examination consist of week index (WI), head circumference (HC), abdominal 
circumference (AC), and $\mathrm{HC} / \mathrm{AC}$ ratio (Figure 2). The WI is the normalized gestational age in terms of weeks between 0 and 40 (e.g., WI for 14 weeks is $14 / 40$, ...etc.). Thus, the input size of fixed NN topology (Table 2) changes with the weekly examinations used in the experiments: A NN with 4 inputs (which is $4 \mathrm{x}$ number of weeks) is used for 1 week experiments, a NN with 8 inputs is used for 2 week experiments. Three outputs are used to represent three cases: normal, sIUGR and aIUGR.

\begin{tabular}{|c|c|c|c|c|c|c|c|c|c|c|}
\hline \multicolumn{2}{|c|}{$\begin{array}{l}\text { Gestational } \\
\text { age }\end{array}$} & \multicolumn{4}{|c|}{ Head circumference } & \multicolumn{5}{|c|}{ Abdominal circumference } \\
\hline weeks & SGA & Normal & LGA & a.IUGR & s.IUGR & SGA & Normal & LGA & a.IUGR & s.IUGR \\
\hline 16 & 11.6 & 13.6 & 16 & 13.6 & 13.6 & 10 & 12.4 & 14.4 & 12.4 & 12.4 \\
\hline 18 & 13.6 & 15.6 & 18 & 15.6 & 15.2 & 12 & 14 & 16.8 & 14 & 13.6 \\
\hline 20 & 15.6 & 18 & 2.0 .4 & 18 & 16.4 & 14 & 16.4 & 19.2 & 16.4 & 15.2 \\
\hline 22 & 17.6 & 20 & 22.8 & 20 & 18 & 16 & 18.4 & 21.2 & 18.4 & 16.4 \\
\hline 24 & 19.6 & 22.4 & 25.2 & 22.4 & 19.6 & 18 & 20.4 & 23.6 & 20 & 18 \\
\hline 26 & 21.6 & 24.4 & 27.2 & 24.4 & 21.6 & 20 & 22.8 & 26 & 22.4 & 20 \\
\hline 28 & 23.6 & 26.4 & 29.2 & 26.4 & 23.6 & 21.6 & 24.8 & 28 & 24 & 21.2 \\
\hline 30 & 25.2 & 28 & 30.8 & 28 & 25.2 & 23.6 & 26.4 & 30 & 24 & 23.2 \\
\hline 32 & 26.8 & 29.6 & 32 & 29.6 & 26 & 25.2 & 28.8 & 32 & 24.4 & 25.2 \\
\hline 34 & 28 & 30.8 & 33.6 & 30.4 & 27.6 & 27.2 & 30.4 & 34 & 24 & 27.2 \\
\hline 36 & 29.2 & 31.6 & 34.4 & 30.8 & 29.2 & 28.4 & 32.4 & 36 & 24 & 28.4 \\
\hline
\end{tabular}

Table 1: Measurements of $\mathrm{HC}$ and $\mathrm{AC}(\mathrm{cm})$ [1].

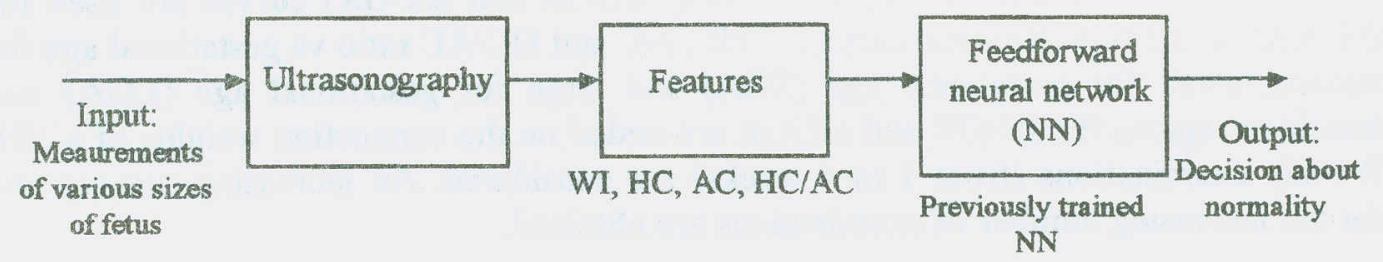

Figure 1: General block diagram of a NN-based IUGR diagnosis system

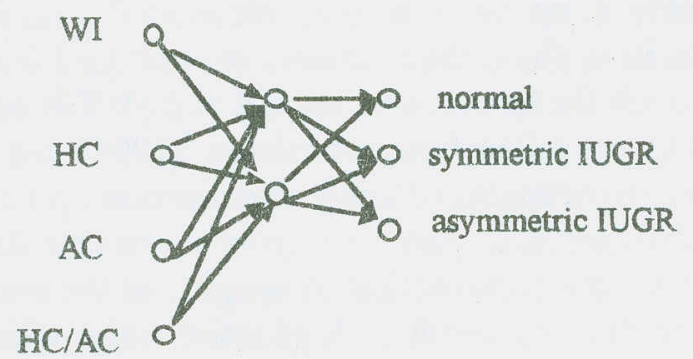

Figure 2: A feedforward NN structure for 1-week input data 


\begin{tabular}{|c|c|c|c|}
\hline $\begin{array}{c}\text { Number of } \\
\text { weeks }\end{array}$ & $\begin{array}{c}\text { Input size } \\
\text { of NN }\end{array}$ & $\begin{array}{c}\text { Number of } \\
\text { hidden } \\
\text { units }\end{array}$ & $\begin{array}{c}\text { Number of } \\
\text { connections }\end{array}$ \\
\hline 1 & 4 & 2 & 14 \\
\hline 2 & 8 & 3 & 33 \\
\hline 3 & 12 & 4 & 60 \\
\hline 4 & 16 & 5 & 95 \\
\hline
\end{tabular}

Table 2: Feedforward NN structures used for the diagnosis of IUGR

\section{Approximation of functions of normal, symmetric and asymmetric IUGR by neural networks}

This study investigates the effects of single and multiple ultrasonographic measurements on the three class decision: normal, sIUGR and aIUGR. Without loss of generality, we assume fixed (predetermined) NN topology with various input sizes of $4,8,12$ and 16. The approximation $\left\{\mathrm{NNw}_{\mathrm{S}}\right\}$ also employs the fixed number of training samples for all the experiments but the number of the weekly measurements are chosen from 1 week to 4 weeks. Thus, if we describe one weekly measurement by $\left(\mathrm{x}_{1 \mathrm{w}} \mathrm{y}_{\mathrm{q}}\right)$ in which $\mathrm{x}_{1 \mathrm{w}}=\{\mathrm{WI}, \mathrm{AC}, \mathrm{HC}, \mathrm{AC} / \mathrm{HC}\}$ and $\mathrm{y}_{\mathrm{q}}=\{$ normal, sIUGR, aIUGR $\}$, the $N N$ is trained by a back propagation (BP) learning algorithm using $\left\{\left(x_{1 w}, y_{q}\right)\right\}$ pairs from the curves and is tested with unseen samples of the same format. The range of gestational age for $x_{1 w}$ is $[16,36]$ (weeks) and $x_{1 w} \varepsilon R^{4}, y_{q} \varepsilon R^{3}$. In two weekly measurements, the training vector pair has a form of $\left\{\left(x_{2 w}, y_{q}\right)\right\}$ where $x_{2 w} \varepsilon R^{8}$ and $y_{q}$ $\varepsilon R^{3}$. The input $x_{2 w}$ has two concatenated components: $\left(x^{\prime}{ }_{1 w} x^{\prime \prime}{ }_{1 w}\right)$ and the range of gestational age for $x^{\prime}{ }_{1 w}$ is $[16,35]$ (weeks) and the range for $x^{\prime \prime}{ }_{1 w}$ is $[17,36]$ (weeks). The inputs of the examinations up to three and four weeks $x_{3 w} \varepsilon R^{12}, x_{4 w} \varepsilon R^{16}$ are constructed in the same manner as $x_{2 w}$

\section{RESULTS}

In this study, it was observed that a feedforward NN structure can be used to approximate the functions of nominal growth curves of fetuses. Furthermore, fetuses with sIUGR and aIUGR can be distinguished from the normal fetuses with up to $95 \%$ accuracy with up to 4 week of ultrasonographic examinations. The $\mathrm{NN}$ as a technique correlates the various types of examinations such as $\mathrm{WI}, \mathrm{AC}, \mathrm{HC} / \mathrm{AC}$ and best models the outcome.

Bi-weekly examinations ( 11 of them) between $16^{\text {th }}$ and $36^{\text {th }}$ gestational weeks that are taken from the nominal curves are used as training data and 150 randomly chosen examinations are employed as test data. Test performances were obtained after a 50000 iterations of training procedure. The success rate, which is the correct diagnosis of IUGR, of the NN using weekly examinations from 1 week up to 4 weeks was shown in Table 3. 


\begin{tabular}{|c|c|c|c|}
\hline $\begin{array}{c}\text { Number of } \\
\text { examinations }\end{array}$ & $\begin{array}{c}\text { Correct } \\
\text { decision } \\
\text { (\# of counts) }\end{array}$ & $\begin{array}{c}\text { Incorrect } \\
\text { decision } \\
\text { (\# of counts) }\end{array}$ & $\begin{array}{c}\text { Success } \\
\text { rate }\end{array}$ \\
\hline 1 weeks & 92 & 58 & $61 \%$ \\
\hline 2 weeks & 119 & 31 & $79 \%$ \\
\hline 3 weeks & 134 & 16 & $88 \%$ \\
\hline 4 weeks & 142 & 8 & $95 \%$ \\
\hline
\end{tabular}

Table 3: The success rate of the NN using weekly examinations

\section{DISCUSSION}

A wide variety of mathematical formulas ( or composite tables) were proposed for the estimation of fetal weight from the ultrasonographic measurements [8]. For these formulas, the timing of the examinations to estimate fetal weight has become controversial due to the poor correlation of early results to the outcomes of several weeks later, and the technical diffuculty and poor reproduction of the late results [9]. Among the attempts to improve accuracy, we may count more accurate estimated fetal weight formulas $[9,11,14]$, the use of single biometric parameter to identify growth abnormalities $[10,12]$, and the use of multiple or serial ultrasonographic examinations to identify individual growth trends $[5,10,12]$.

The study confirms the following results:

1. In the ultrasound examinations, multiple parameters (such $\mathrm{HC}, \mathrm{AC}$ and $\mathrm{HC} / \mathrm{AC}$ ) are better than the prediction with a single parameter. Parameters such as $B P D$, femur length (FL) may also be employed.

2. The experiment results also show that multiple examinations give a better insight for the diagnosis of IUGR than a single examination.

3. A NN is a very helpful tool for correlating many variables that, taken alone, may not be statistically significant but as a group provide additional information to make the best decision.

The following comments are made:

1. The outputs of the $\mathrm{NN}$ can be defined to show only normal and retarded fetal growth cases.

2. The NN which is used here supports decision of doctors on the diagnosis of IUGR does not compete with them.

As a future work, the following are planned:

1. A composite of BPD, FL, HC, AC, HC/AC may be used to improve predictive accuracy and IUGR diagnosis. These parameters may also be presented to the input of NN.

2. We expect to perform same experiments on the decision of IUGR by NN using data obtained by the ultrasound examinations of patients in Obstet. and Gynecol. departments. 
Finally, this study concludes that NNs are proven to be advantageous tools for the determination of IUGR and this application is a fruitful line of inquiry for further work.

\section{REFERENCES}

1. Chudleigh P. and Pearce J. M., "Obstetric ultrasound: how, why and when," Newyork, Churchill Livingstone, 1986.

2. Crouse D. T., Cassady G., "The Small-for-Gestational-Age Infant," Neonatalogy: Pathophysiology and Management of Newborn, Fourth Edition, Ed. by G. B. Avery, M. A. Fletcher, and M. G. MacDonald, J.B. Lippincott Comp., Philadelphia, 1994.

3. Farmer R. M., et al. "The use of a neural network for the ultrasonographic estimation of fetal weight in the macrosomic fetus," Am. J. Obstet. Gynecol., Vol. 16, No. 5, pp.1467-1472, 1992.

4. Gabbe S. G., Iams J. D., "Intrauterine Growth Retardation,” Chapter 12, Ob/Gyn by Zuspan F., Iams Jay, pp. 165-172, Mosby Publ., USA, 1991.

5. Gallivan S., Robson S.C., Chang T.C., Vaughan J., Spencer J.A.D., "An investigation of fetal growth using serial ulirasound data," Obstet Gynecol, 3, pp 109 114, 1993.

6. Gürgen F. S., M. Şıłmanoğh, Varol F. G., "The assessment of LH surge for predicting ovulation time using clinical, hormonal and ultrasonic indices in infertile women with an ensemble of neural networks," Comp. Biol. Med. Vol. 25, No. 4, pp. $405-413,1995$.

7. Gürgen F. S., Alpaydin R., Ünlüakın U., Alpaydin E., "Distributed and local neural classifiers for phoneme recognition," Pattern Recognition Letters 15, pp. 1111$1118,1994$.

8. Hedriana H. L. and Moore T. R. "A comparison of single versus multiple growth ultrasonographic examinations in predicting birth weight," Am. J. Obstet. Gynecol., Vol. 170, No. 6, pp.1600-1606, 1994.

9. Hirata G. I., Medearis A. L., Horenstein J., Bear M. B., Platt L.D., "Ultrasonographic estimation of fetal weight using real-time ultrasound," Am. J. Obstet. Gynecology, 162, pp. 238-242, 1990.

10. Pedersen J. F., Molsted-Pedersen L., "Sonographic estimation of fetal weight in diabetic pregnancy," Br. J. Obstet. Gynecol., 99, pp. 475-478, 1992.

11. Shepard M.J., Richards V.A., Berkowitz R.L., Warsof S.L., Hobbins J.C., "An evaluation of two equations for predicting fetal weight by ultrasound," Am. J. Obstet. Gynecol., 142, pp. 47-54, 1982.

12. Shields L.E., Huff R.W., Jackson G.M., Olive D.L., Patterson R.M., "Fetal growth: a comparison of curves with mathematical modeling," J. Ultrasound Med., 5, pp. 271-274, 1993.

13. Smagt P. P. Van Der, "Minimisation Methods for Training Feedforward Neural Networks," Neural Networks, Vol. 7, N0. 1, pp. 1-11, 1994.

14. Warsof S.L., Gohari P., Berkowitz R.L., Hobbins J.C., "The estimation of fetal-weight by computer assisted analysis," Am. J. Obstet. Gynecol, 128, pp. 881-892, 1977. 